\title{
SELEÇÃO DE CRITÉRIOS PARA A ESPECIFICAÇÃO DE PASTAS CELULÓSICAS BRANQUEADAS DE EUCALIPTOS NA FABRICAÇÃ̃O DE PAPÉIS PARA IMPRESSÃO "OFFSET"
}

\section{CRITERIA SELECTION FOR BLEACHED EUCALYPT KRAFT PULP SPECIFICATION ORIENTED TO THE MANUFACTURE OF OFFSET PAPERS}

\author{
Edison da Silva Campos ${ }^{1}$ Marco Aurélio Luiz Martins ${ }^{2}$ \\ Celso Edmundo Bochetti Foelkel ${ }^{3}$ Sonia Maria Bitencourt Frizzo $^{4}$
}

\begin{abstract}
RESUMO
Este estudo procurou analisar as características de algumas pastas celulósicas branqueadas de eucaliptos disponíveis no mercado e seu impacto nas propriedades dos papéis utilizados para impressão "offset". Também buscou estudar formas para reduzir o número de testes laboratoriais que hoje são definidos como necessários para a caracterização desses recursos fibrosos. Foram analisadas treze pastas celulósicas de mercado, brasileiras e internacionais, aplicando-se testes de viscosidade intrínseca, solubilidade em solução de $\mathrm{NaOH}_{5 \%}\left(\mathrm{~S}_{5}\right)$, "coarseness", número de fibras/g, comprimento médio das fibras, teor de finos pelo vaso de drenagem dinâmica e grau Schopper Riegler ( $\left.{ }^{\circ} \mathrm{SR}\right)$, antes das pastas serem refinadas. Foram também aplicados testes para determinar o índice de tração, alongamento, índice de arrebentamento, índice de rasgo, volume específico, resistência ao ar, opacidade, alvura e ascensão capilar Klemm, para cada uma das pastas antes de refinar e para os níveis de refino de $25^{\circ} \mathrm{SR}, 30^{\circ} \mathrm{SR}, 40^{\circ} \mathrm{SR}$ e $55^{\circ} \mathrm{SR}$. As celuloses de eucaliptos brasileiras apresentaram uma maior drenabilidade inicial (pasta ainda não-refinada), requerendo um menor número de revoluções do refinador PFI para atingir o mesmo grau de refino, em relação às polpas internacionais estudadas. Os valores médios iniciais do alongamento, do índice de tração, do índice de arrebentamento e do índice de rasgo, apresentados pelas celuloses brasileiras, superaram significativamente os obtidos para as celuloses internacionais, mudando, porém, esse comportamento já a partir do nível de $25^{\circ} \mathrm{SR}$. Nas faixas de $\mathrm{S}_{5}$ e viscosidade intrínseca apresentadas pelas polpas brasileiras e internacionais, não se evidenciou sua correlação com as propriedades associadas ao grau de interligação entre as fibras, tais como índice de tração, índice de rasgo e índice de arrebentamento, para cada grupo de polpas analisadas. Os resultados obtidos permitiram definir o critério de ensaio a $30^{\circ} \mathrm{SR}$ como o melhor em conseqüência do maior número de correlações entre as várias propriedades avaliadas antes e após a refinação. Nesse nível, as polpas internacionais apresentaram significativamente maiores valores médios de índice de tração e
\end{abstract}

1. Engenheiro Eletricista, M.Sc., Programa de Pós-Graduação em Engenharia Florestal, Centro de Ciências Rurais, Universidade Federal de Santa Maria, CEP 97105-900, Santa Maria (RS). Consultor Técnico da Unidade de Fabricação da Empresa Riocell S.A.,Guaíba (RS).

2. Engenheiro Químico, M.Sc., Consultor Técnico da Diretoria de Comercialização da Riocell S.A., CEP 92500000, Guaíba (RS).

3. Engenhairo Agrônomo, Dr.h.c., Professor Visitante do Departamento de Ciências Florestais, Centro de Ciências Rurais, Universidade Federal de Santa Maria, CEP 97105-900, Santa Maria (RS).

4. Engenheiro Florestal, M.Sc., Professora do Departamento de Química, Centro de Ciências Naturais e Exatas, Universidade Federal de Santa Maria, CEP 97105-900, Santa Maria (RS). 
índice de rasgo do que as brasileiras, enquanto as polpas brasileiras apresentaram maior valor médio de opacidade e menor consumo médio de energia de refino. Em termos de qualificação laboratorial, sugeriu-se que as análises de índice de tração e rasgo e opacidade fossem definidas como prioritárias para comparação e caracterização desse tipo de pastas celulósicas, quando o objetivo final é a produção de papéis de impressão "offset".

Palavras-chaves: eucalipto, papéis para impressão , papel "offset", celulose, pastas celulósicas.

\begin{abstract}
The purpose of this work was to analyze the characteristics of some eucalypts pulps available in the market, aiming to understand their influence in the properties of the offset papers. Another objective of this work was to show alternatives to reduce the number of laboratory tests in the pulp specifications. Thirteen (13) market pulps (Brazilian and international pulps) were analyzed and the tests applied were as follows: intrinsic viscosity, alkali solubility at $5 \%$, coarseness, numbers of fibers per gram of pulp, average length of fibers, fine fraction by the Dynamic Paper Chemistry Jar (DPCJ), drainability by Schopper Riegler, before refining. Other tests, such as: tensile index, stretch, burst index, tear index, bulk, air resistance, opacity and absorption of water by cappilarity (Klemm) were performed for each type of pulp before refining and for refining levels of $25^{\circ} \mathrm{SR}, 30^{\circ} \mathrm{SR}, 40^{\circ} \mathrm{SR}$ and $55^{\circ} \mathrm{SR}$. No evidence of the influence of $\mathrm{S}_{5}$ and intrinsic viscosity was observed at the range of the market pulp properties variation. The Brazilian pulps presented higher initial drainability and required lower PFI revolutions to the same level of refining in comparison to the international pulps. The initial average values of strength indexes: tensile, stretch, burst and tear were higher to the Brazilian pulps. However, this situation was changed at $25^{\circ} \mathrm{SR}$ and other levels of drainability. Due to the higher number of correlations at $30^{\circ} \mathrm{SR}$, this level of drainability was chosen to determine the pulp characteristics profile. At this level, international pulps showed better values of tensile and tear index, but a higher energy consumption and a lower opacity in comparison to the Brazilian pulps. In addition, this paper suggested the concentration of the lab technical evaluation of pulps on the analysis of opacity, tensile and tear indexes. Such procedure should reduce the number of lab tests as well.
\end{abstract}

Key words: eucalypt, offset papers, printing papers, pulps.

\title{
INTRODUÇÃO
}

Para ROSSI FILHO (1997), o papel deve reunir uma série de propriedades que garantam sua imprimibilidade e seu desempenho durante os processos de impressão e acabamento, bem como atendam aos requisitos de uso final. De maneira abrangente, as propriedades, relacionadas à imprimibilidade, podem ser classificadas em: propriedades de aparência (alvura, brilho, opacidade), propriedades químicas ( $\mathrm{pH}$, ausência de produtos químicos ativos), propriedades estruturais (gramatura, espessura, volume específico, absorção, porosidade, compressibilidade, direção de 
fibras, planura, estabilidade dimensional), propriedades mecânicas (resistência à tração, resistência ao estouro, resistência ao rasgo, resistência a dobras duplas, teor de umidade) e propriedades superficiais (lisura, resistência ao arrancamento).

Para saber-se quais são as propriedades realmente importantes em uma pasta celulósica, com respeito ao papel que foi produzido com base nela, as condições de simulação da fabricação do papel deveriam corresponder tão rigorosamente quanto possível às condições reais de produção (LEVLIN, 1975). Isso é uma tarefa difícil, em parte, porque o papel é feito em condições diferentes, em diversos sistemas de produção, e, em parte, por causa das dificuldades na simulação da produção de papel em escala laboratorial.

ANNIKKI et al. (1990) reforçam essa idéia, afirmando que, em termos de produção da folha, as principais diferenças entre as folhas feitas em laboratório e a produção de papel em larga escala estão na formação na mesa plana, prensagem a úmido e secagem. No laboratório, a folha é formada com base em uma suspensão muito diluída, usando procedimento de desaguamento lento e de baixa pressão, seguido por uma secagem lenta. Isso significa que a estrutura da folha feita em laboratório será bastante diferente da produzida por uma máquina de papel, não levando em conta, ainda, a calandragem em máquina a qual fornece características superficiais à folha de papel, diferentes das que são obtidas normalmente em laboratório.

TASMAN (1992) afirma que, por causa das complexas interações entre as variáveis envolvidas na produção de folhas manuais, o problema de relacionar propriedades dessas folhas às características da pasta celulósica é uma grande dificuldade. Entretanto, para SETH (1991), a resistência intrínseca das fibras, o "coarseness" e o comprimento médio das fibras são identificadas como importantes propriedades físicas das fibras que compõem a pasta celulósica, tanto para o papel fabricado em escala laboratorial como em uma máquina de papel. Já para SCOTT \& TROSSET (1989), a resistência intrínseca das fibras contribui para todas as propriedades mecânicas da folha de papel produzida com base nessas fibras. Essa resistência intrínseca da fibra é usualmente medida pelo teste de tensão "zero-span" e, muitas vezes, de forma indireta, pela viscosidade da fibra dissolvida. D'ALMEIDA (1986) intensifica essa afirmação, dizendo que o valor da viscosidade de uma pasta celulósica, por ser uma medida indireta do grau de polimerização médio das moléculas de celulose que constituem as fibras desta pasta, pode ser também um indicativo da resistência intrínseca das fibras, dentro de certos limites.

HORTAL (1988) afirma que o "coarseness" de uma fibra, definido como a massa por unidade de comprimento, é uma propriedade fundamental que afeta algumas das propriedades de aparência, estruturais, mecânicas e superficiais do papel. Para KEREKES \& SCHELL (1995), o "coarseness" exerce também sua influência na uniformidade da folha por meio do número de contatos por fibras, tamanho dos flocos e mobilidade das fibras durante a formação. Uma alteração no valor de "coarseness" influencia significativamente todas as propriedades da pasta celulósica tais como drenagem, resistência a úmido, propriedades estruturais, mecânicas e de aparência da folha seca (SETH, 1991).

Com respeito ao comprimento médio da fibra, YOUNG (1980) afirma que esse parâmetro afeta a formação ou uniformidade da distribuição das fibras. Quanto mais curtas forem as fibras, mais uniforme será a formação da folha e melhor sua estabilidade dimensional, por exemplo. O 
comprimento médio das fibras também afeta as propriedades mecânicas da folha de papel produzida. A resistência ao rasgo, por exemplo, decresce com o decréscimo no comprimento médio da fibra.

Além das propriedades intrínsecas das fibras evidenciadas acima, SETH (1991) afirma também que os parâmetros que descrevem o estado de ligação das fibras em uma rede têm sido incluídos em estudos, de forma a se tornarem aptos a predizer as propriedades do papel. Usando esses parâmetros, a resistência e o potencial ótico das polpas podem ser estimados e as propriedades das diferentes polpas comparadas. Segundo RETULAINEN \& EBELING (1993), a propriedade de ligação entre fibras é a chave para a coesão interna do papel. Quase todas as interações mecânicas entre as fibras durante a fabricação do papel toma lugar por meio das ligações das fibras.

CARPIM (1987) et al. notaram que as propriedades, que dependem do grau de ligação entre fibras como densidade aparente e as resistências à tração e ao arrebentamento, mostraram maiores índices nas polpas com mais fibras por grama. Isso comprova que essa característica proporciona mais pontos de contato, aumentando o número de ligações. Ao mesmo tempo, observa-se, nessas polpas, maior resistência ao ar Gurley. Para NEVELL \& ZERONIAN (1985), a refinação produz fibrilação interna, externa e corte das fibras cuja consequiência é o aumento do número e das áreas de ligações entre fibras.

SAUCEDO \& GONZÁLEZ (1981) relatam que o conteúdo de hemiceluloses na polpa torna as fibras e as fibrilas mais susceptíveis à ação de refino, produzindo fibrilação em lugar de corte. Isso colabora para melhor ligação entre fibras. Por causa do grande número de flexões que sofre a fibra, são afetadas algumas das ligações internas, resultando no que se conhece como fibrilação interna. Para JIMÉNEZ (1970), uma das maneiras indiretas de se avaliar o teor de hemiceluloses é medir a solubilidade da pasta em solução concentrada de $\mathrm{NaOH}\left(\mathrm{S}_{5}\right.$, por exemplo). Altos níveis de refinação da polpa podem também causar efeitos adversos tais como degradação da resistência da fibra, em razão dos danos físicos causados a ela (DASGUPTA ,1994),

Em conseqüência do que foi exposto pelo autores acima referenciados, neste trabalho, optouse por analisar algumas propriedades intrínsecas das fibras, tais como "coarseness" e comprimento médio das fibras; propriedades intrínsecas da pasta celulósica, tais como viscosidade intrínseca, $\mathrm{S}_{5}$, número de fibras por grama, teor de finos DPCJ e ${ }^{\circ} \mathrm{SR}$ inicial (sem refinar), buscando correlacionálas com propriedades da folha formada sem refinação e para alguns níveis de refino, tais como índice de tração, índice de rasgo, volume específico, etc. As pastas celulósicas analisadas foram divididas em dois grandes grupos: brasileiras e internacionais os quais foram comparadas em termos das propriedades das folhas formadas com base nessas pastas.

\section{MATERIAL E MÉTODOS}

\section{Amostragem}

O trabalho foi realizado com treze amostras de pastas celulósicas de mercado, produzidas por fabricantes do Brasil e do exterior (Chile, Portugal e Espanha), todas valendo-se de eucalipto. As celuloses eram branqueadas e tornadas disponíveis regularmente aos fabricantes de papéis de 
impressão e escrita no mercado mundial. Tanto os fabricantes como a origem das celuloses foram omitidos para evitar eventuais comparações indesejáveis entre fabricantes. Dessa forma, as diferentes amostras foram tratadas como dois grandes grupos: brasileiras e internacionais.

As amostras constituíram-se de folhas retangulares de celulose. Para realização das análises retirou-se cerca de $1 \mathrm{~cm}$ de cada um dos quatro lados da folha, rasgando-a manualmente e utilizando-se o restante, conforme método descrito pela norma da TECHNICAL ASSOCIATION OF PULP AND PAPER INDUSTRY (TAPPI 400 om - 85).

As determinações físico-químicas foram realizadas nos laboratórios do Centro Tecnológico da Riocell S.A., desde a preparação, ensaios e análises das amostras. Para efeito do presente estudo, foram selecionadas propriedades mais típicas e mais comumente avaliadas em polpas para fabricação de papel. O refino das polpas foi realizado em moinho PFI, conforme metodologia da INTERNATIONAL ORGANIZATION FOR STANDATIZATION (ISO 5264-2 : 1979).

\section{Propriedades testadas}

As propriedades testadas, para cada uma das pastas sem refinar, foram: viscosidade intrínseca, de acordo com metodologia ISO 5351-1 : 1981; solubilidade em solução de $\mathrm{NaOH}_{5 \%}$ $\left(\mathrm{S}_{5}\right)$, de acordo com metodologia ISO 692 : 1982; "coarseness" e número de fibras/g, de acordo com o manual de operações do aparelho KAJAANI FS-100 FIBER SIZE ANALIZER; comprimento médio das fibras e teor de finos pelo vaso dinâmico de drenagem (DPCJ) foram determinados conforme procedimentos do DYNAMIC PAPER CHEMISTRY JAR ${ }^{\mathrm{tm}}$ OPERATING MANUAK MARK III; grau Schopper Riegler ( $\left.{ }^{\circ} S R\right)$, de acordo com metodologia ISO 5267-1 : 1979; índice de tração, de acordo com metodologia ISO 1924 : 1992; alongamento, de acordo com metodologia ISO 1974 : 1990; índice de arrebentamento, de acordo com metodologia TAPPI 403 om-91; índice de rasgo, de acordo com metodologia ISO 1974 : 1990; volume específico, de acordo com metodologia RIOCELL DT 8020-07-113-3, adaptada das normas TAPPI 411 om-89 e ISO 536 : 1979; resistência ao ar, de acordo com metodologia TAPPI 460 om-88; alvura e opacidade e de acordo com metodologia ISO 2470 : 1972, e ascensão capilar Klemm de acordo com metodologia RIOCELL DT 8020-07-172-3.

Após refinação, a cada um dos níveis de $25^{\circ} \mathrm{SR}, 30^{\circ} \mathrm{SR}, 40^{\circ} \mathrm{SR}$ e $55^{\circ} \mathrm{SR}$, foram feitos somente os testes de índice de tração, alongamento, índice de arrebentamento, índice de rasgo, volume específico, resistência ao ar, opacidade, alvura e ascensão capilar Klemm.

As medições das características anatômicas das fibras resultantes foram classificadas em dois tipos fundamentais: "com corte" e "sem-corte", tanto para o número de fibras quanto para o "coarseness". Segundo EQUIPE DEPTEC (1989), denomina-se medição "sem-corte", quando o aparelho considera em suas medições qualquer partícula como unitária para efeitos de contagem, independentemente de seu tamanho. No caso da denominação "com corte", o aparelho somente considera como unitárias as partículas cujo comprimento for superior a $0,25 \mathrm{~mm}$.

\section{Análise estatística dos resultados}

Todos os dados obtidos foram analisados estatisticamente por meio de comparação de 
médias, por Análise de Variância com significância de 5\% de probabilidade, por meio da Análise de Dados, planilha eletrônica EXCEL - Microsoft. Para os ensaios feitos após a refinação, foram construídas tabelas de correlação ao nível de 5\% de significância, utilizando a Análise de Dados do EXCEL.

\section{RESULTADOS E DISCUSSÃO}

\section{Avaliações laboratoriais das celuloses}

As treze amostras de celulose foram avaliadas laboratorialmente, levando em consideração todas as suas propriedades. Posteriormente, para verificar se haviam diferenças significativas entre as médias dos valores das propriedades pertencentes às polpas brasileiras e internacionais, foi feita uma análise ANOVA, utilizando a Análise de Dados do EXCEL cuja síntese está representada na Tabela 1. É importante ressaltar algumas observações referentes a essa Tabela:

- para a maioria dos casos, o F crítico a um nível de 5\% de significância foi definido como sendo 4,84 , correspondendo ao grau de liberdade dentro do grupos igual a 11. Houve exceção para os casos indicados com número sobrescrito ( F crítico $=5,12$ ), correspondendo ao grau de liberdade dentro do grupos igual a 9 .

- foram definidos com um asterisco os casos em que houve diferenças significativas entre as médias, ao nível de significância de $5 \%$. Nesse caso, foi anotado o (*) logo após o valor de F na Tabela 1.

TABELA 1: Resumo da análise ANOVA para variáveis em estudo.

\begin{tabular}{|c|c|c|c|c|c|}
\hline POLPAS DE MERCADO & \begin{tabular}{|c|} 
Médias \\
Brasileiras \\
\end{tabular} & $\begin{array}{l}\mathrm{CV} \\
(\%) \\
\end{array}$ & \begin{tabular}{|c|} 
Médias \\
Internacionais
\end{tabular} & $\begin{array}{l}\mathrm{CV} \\
(\%) \\
\end{array}$ & $\mathrm{F}$ \\
\hline VISCOSIDADE INTRÍNSECA (cm3/g) & 755,13 & 8,88 & 809,60 & 8,84 & 1,93 \\
\hline S5 (\%) & 10,30 & 12,67 & 12,53 & 7,33 & $10,98^{*}$ \\
\hline COARSENESS $(\mathrm{mg} / 100 \mathrm{~m})$ com corte & 5,98 & 9,53 & 6,93 & 7,73 & $9,01 *$ \\
\hline COARSENESS $(\mathrm{mg} / 100 \mathrm{~m})$ sem corte & 5,96 & 10,81 & 6,84 & 7,54 & $6,64 *$ \\
\hline NÚMERO DE FIBRAS/g (milhões) com corte & 24,21 & 8,41 & 19,46 & 6,49 & $21,51 *$ \\
\hline NÚMERO DE FIBRAS/g (milhões) sem corte & 24,54 & 11,36 & 19,64 & 5,94 & $13,57 *$ \\
\hline COMPRIMENTO MÉDIO DA FIBRA (mm) & 0,70 & 3,81 & 0,75 & 2,19 & $16,67 *$ \\
\hline TEOR DE FINOS DPCJ (\%) & 9,56 & 8,20 & 8,98 & 11,12 & 1,33 \\
\hline ºR (POLPA NÃO REFINADA) & 23,00 & 8,70 & 17,80 & 4,70 & $29,71 *$ \\
\hline No. REVOLUÇÕES PDI (x1000) $\left(25^{\circ} \mathrm{SR}\right)$ & 0,23 & 72,51 & 1,03 & 21,60 & $46,15^{* 1}$ \\
\hline No. REVOLUÇÕES PFI ( x1000) $\quad\left(30^{\circ} \mathrm{SR}\right)$ & 0,70 & 55,88 & 1,74 & 23,56 & $21,29 *$ \\
\hline No. REVOLUÇÕES PFI (x1000) $\left(40^{\circ} \mathrm{SR}\right)$ & 1,99 & 31,93 & 3,08 & 19,50 & $9,33 *$ \\
\hline
\end{tabular}

Continua ..... 
TABELA 1: Continuação ....

\begin{tabular}{|c|c|c|c|c|c|}
\hline POLPAS DE MERCADO & $\begin{array}{c}\text { Médias } \\
\text { Brasileiras }\end{array}$ & $\begin{array}{l}\mathrm{CV} \\
(\%) \\
\end{array}$ & \begin{tabular}{|c|} 
Médias \\
Internacionais \\
\end{tabular} & $\begin{array}{l}\mathrm{CV} \\
(\%) \\
\end{array}$ & $\mathrm{F}$ \\
\hline No. VEROLUÇÕES PFI ( x1000) $\left(55^{\circ} \mathrm{SR}\right)$ & 4,10 & 35,99 & 4,72 & 17,03 & 0,73 \\
\hline ÍNDICE DE TRAÇÃ̃ (N.m/g) & 29,06 & 22,69 & 21,10 & 11,60 & $6,53 *$ \\
\hline ÍNDICE DE TRAÇÃO (N.m/g) (25 ºR) & 36,20 & 9,75 & 54,98 & 3,631 & $110,72^{* 1}$ \\
\hline ÍNDICE DE TRAÇÃO (N,m/g) (30 SR) & 52,59 & 4,39 & 67,54 & 2,471 & $156,54^{*}$ \\
\hline ÍNDICE DE TRAÇÃO $(\mathrm{N}, \mathrm{m} / \mathrm{g})\left(40^{\circ} \mathrm{SR}\right)$ & 79,06 & 6,92 & 81,10 & 2,74 & 0,61 \\
\hline ÍNDICE DE TRAÇÃO $(\mathrm{N}, \mathrm{m} / \mathrm{g})\left(55^{\circ} \mathrm{SR}\right)$ & 90,85 & 9,12 & 93,68 & 5,95 & 0,45 \\
\hline ALONGAMENTO $(\%)$ & 1,81 & 11,59 & 1,26 & 16,46 & $21,49 *$ \\
\hline ALONGAMENTO (\%) $\left(25^{\circ} \mathrm{SR}\right)$ & 2,12 & 6,95 & 2,28 & 10,47 & $1,94^{1}$ \\
\hline ALONGAMENTO (\%) (30 $\left.{ }^{\circ} \mathrm{SR}\right)$ & 2,70 & 9,29 & 2,90 & 12,43 & 1,41 \\
\hline ALONGAMENTO (\%) (40 $\left.{ }^{\circ} \mathrm{SR}\right)$ & 3,61 & 9,97 & 3,50 & 8,81 & 0,33 \\
\hline ALONGAMENTO $(\%)\left(55^{\circ} \mathrm{SR}\right)$ & 4,20 & 11,02 & 4,08 & 9,07 & 0,24 \\
\hline ÍNDICE DE ARREBENTAMENTO (kPa. m2/g) & 1,14 & 48,82 & 0,38 & 39,03 & $8,64 *$ \\
\hline ÍNDICE DE ARREBENTAMENTO (25 $\left.{ }^{\circ} \mathrm{SR}\right)$ & 1,52 & 28,41 & 2,20 & 7,19 & $11,15^{* 1}$ \\
\hline ÍNDICE DE ARREBENTAMENTO (30 SR) & 2,71 & 20,99 & 3,18 & 7,83 & 2,93 \\
\hline ÍNDICE DE ARREBENTAMENTO (40 으) & 4,91 & 17,42 & 4,46 & 6,46 & 1,26 \\
\hline ÍNDICE DE ARREBENTAMENTO (55 으) & 6,38 & 15,11 & 5,93 & 11,47 & 0,81 \\
\hline ÍNDICE DE RASGO (mN.m2/g) & 5,46 & 21,50 & 3,18 & 16,99 & $16,29 *$ \\
\hline ÍNDICE DE RASGO (mN,m2/g) $\left(25^{\circ} \mathrm{SR}\right)$ & 7,07 & 11,09 & 9,22 & 6,30 & $25,74 * 1$ \\
\hline ÍNDICE DE RASGO $(\mathrm{mN}, \mathrm{m} 2 / \mathrm{g})\left(30^{\circ} \mathrm{SR}\right)$ & 9,54 & 5,66 & 11,06 & 7,63 & $16,04 *$ \\
\hline ÍNDICE DE RASGO (mN,m2/g) (40 요 & 12,45 & 6,77 & 12,00 & 3,86 & 1,17 \\
\hline ÍNDICE DE RASGO (mN,m2/g) $\left(55^{\circ} \mathrm{SR}\right)$ & 12,10 & 3,59 & 11,68 & 4,26 & 2,59 \\
\hline VOLUME ESPECÍFICO (cm3/g) & 2,14 & 4,89 & 2,44 & 1,99 & $35,09 *$ \\
\hline VOLUME ESPECÍFICO (cm3/g) (25 요) & 2,01 & 4,33 & 1,95 & 2,64 & $2,02^{1}$ \\
\hline VOLUME ESPECÍFICO (cm3/g) (30 ㅇR) & 1,84 & 3,20 & 1,83 & 2,88 & 0,17 \\
\hline VOLUME ESPECÍFICO (cm3/g) (40 ㅇR) & 1,63 & 2,25 & 1,71 & 1,74 & $16,68 *$ \\
\hline VOLUME ESPECÍFICO (cm3/g) (55 요) & 1,50 & 2,82 & 1,60 & 1,42 & $22,27 *$ \\
\hline RESISTÊNCIA AO AR (s/100 cm3) & 1,38 & 28,50 & 0,52 & 8,60 & $22,85^{*}$ \\
\hline RESISTÊNCIA AO AR (s/100 cm3) (25 'SR) & 2,25 & 28,77 & 1,56 & 15,44 & $5,02^{1}$ \\
\hline RESISTÊNCIA AO AR (s/100 cm3) (30 $\left.{ }^{\circ} \mathrm{SR}\right)$ & 4,29 & 31,94 & 3,44 & 7,30 & 1,82 \\
\hline RESISTÊNCIA AO AR (s/100 cm3) (40 요) & 17,15 & 24,26 & 10,70 & 17,74 & $10,38 *$ \\
\hline RESISTÊNCIA AO AR (s/100 cm3) (55 요) & 61,78 & 22,96 & 42,32 & 23,07 & $7,16^{*}$ \\
\hline OPACIDADE $(\%)$ & 81,19 & 0,59 & 79,88 & 0,38 & $29,57 *$ \\
\hline OPACIDADE $(\%)\left(25^{\circ} \mathrm{SR}\right)$ & 80,35 & 0,59 & 77,04 & 1,07 & $69,54 * 1$ \\
\hline OPACIDADE $(\%)\left(30^{\circ} \mathrm{SR}\right)$ & 79,30 & 0,85 & 76,16 & 1,43 & $41,96^{*}$ \\
\hline OPACIDADE $(\%)\left(40^{\circ} \mathrm{SR}\right)$ & 76,75 & 1,34 & 74,80 & 1,57 & $9,95 *$ \\
\hline OPACIDADE $(\%)\left(55^{\circ} \mathrm{SR}\right)$ & 74,58 & 1,14 & 73,36 & 1,11 & $6,43 *$ \\
\hline ALVURA (\% ISO) & 89,10 & 1,85 & 89,12 & 1,01 & 0,00 \\
\hline ALVURA (\% ISO) ( $\left.25^{\circ} \mathrm{SR}\right)$ & 89,73 & 0,58 & 88,36 & 1,16 & $8,32 *^{1}$ \\
\hline
\end{tabular}


TABELA 1: Continuação ....

\begin{tabular}{|c|c|c|c|c|c|}
\hline POLPAS DE MERCADO & \begin{tabular}{|c|} 
Médias \\
Brasileiras
\end{tabular} & $\begin{array}{l}\mathrm{CV} \\
(\%)\end{array}$ & \begin{tabular}{|c|} 
Médias \\
Internacionais
\end{tabular} & $\begin{array}{l}\mathrm{CV} \\
(\%)\end{array}$ & $\mathrm{F}$ \\
\hline ALVURA (\% ISO) (30 $\left.{ }^{\circ} \mathrm{SR}\right)$ & 88,45 & 1,77 & 87,90 & 1,30 & 0,46 \\
\hline ALVURA (\% ISO) (40 $\left.{ }^{\circ} \mathrm{SR}\right)$ & 87,76 & 2,00 & 87,40 & 1,52 & 0,16 \\
\hline ALVURA (\% ISO) (55 $\left.{ }^{\circ} \mathrm{SR}\right)$ & 86,48 & 2,31 & 86,66 & 1,08 & 0,04 \\
\hline ASCENÇÃO CAPILAR KLEMM (mm/10 min) & 91,75 & 7,29 & 119,00 & 2,45 & $72,32 *$ \\
\hline $\begin{array}{l}\text { ASCENÇÃO CAPILAR KLEMM (mm/10 min) (25 } \\
{ }^{\circ} \text { SR) }\end{array}$ & 78,67 & 8,46 & 85,40 & 4,43 & $4,00^{1}$ \\
\hline $\begin{array}{l}\text { ASCENÇÃO CAPILAR KLEMM (mm/10 min) (30 } \\
{ }^{\circ} \text { SR) }\end{array}$ & 64,88 & 13,40 & 67,40 & 7,75 & 0,34 \\
\hline $\begin{array}{l}\text { ASCENÇÃO CAPILAR KLEMM (mm/10 min) (40 } \\
\left.{ }^{\circ} \mathrm{SR}\right)\end{array}$ & 40,63 & 13,98 & 44,60 & 7,37 & 1,99 \\
\hline $\begin{array}{l}\text { ASCENÇÃO CAPILAR KLEMM (mm/10 min) (55 } \\
{ }^{\circ} \mathrm{SR} \text { ) }\end{array}$ & 25,38 & 12,63 & 28,00 & 3,57 & 3,17 \\
\hline
\end{tabular}

Em que: ${ }^{1}=\mathrm{F}$ crítico $=5,12 ; \mathrm{CV}=$ Coeficiente de variação; $\mathrm{F}=$ valor de $\mathrm{F}$ calculado; ${ }^{*}=$ siguinificativo ao nivel de $5 \%$ de probabilidade de erro.

A seguir, foi feita análise dos resultados dos ensaios realizados para as propriedades consideradas nos diversos níveis de refino. Paralelamente a essa análise, foram plotadas as mesmas propriedades como função da resistência à drenabilidade e eventualmente de outra propriedade de significância para a destinação do papel. A escolha da resistência à drenabilidade se deve-se ao referencial que representa cada nível de refino para a execução dos ensaios. A utilização referencial das demais propriedades como viscosidade intrínseca, $\mathrm{S}_{5}$, "coarseness", número de fibras por grama, comprimento médio de fibra e teor de finos DPCJ será feita oportunamente, a medida em que for analisada cada propriedade.

Pela Tabela 1, se percebe que as médias das propriedades das polpas brasileiras e internacionais diferem significativamente, enquanto ainda não foram refinadas, diminuindo a diferença à medida que se aumenta o grau de refinação.

O coeficiente de variação do número de revoluções, para as diversas propriedades, foram extremamente elevadas em todos os níveis de refino, mas com tendência a decrescer à medida que se aumentam os níveis de refinação.

Conforme a Figura 1, o número das revoluções necessárias para atingir determinada resistência à drenabilidade é maior para as polpas internacionais do que para as polpas brasileiras. Em outras palavras, gasta-se menos energia para refinar as polpas brasileiras. Um dado importante, que pode explicar a maior facilidade em refinar as polpas brasileiras, é que, inicialmente, essas polpas possuíam maior resistência à drenabilidade, maior número inicial de fibras por grama, menor comprimento médio das fibras e menores valores de "coarseness" em relação às polpas internacionais.

O índice de tração inicial (polpas não-refinadas) das polpas brasileiras apresenta média maior em relação às internacionais. Entretanto, já para os níveis de $25^{\circ} \mathrm{C} \mathrm{e} 30^{\circ} \mathrm{C}$, as polpas internacionais superam significativamente as médias de tração das polpas brasileiras. Para os níveis de $40^{\circ} \mathrm{C}$ e $55^{\circ} \mathrm{C}$, as médias de tração das polpas brasileiras e internacionais não são significativamente diferentes. Como nas fábricas de papel para impressão e escrita com base em celuloses de eucalipto, trabalham- 
se com níveis de refino na faixa $\operatorname{dos} 30^{\circ} \mathrm{C}$, as polpas internacionais avaliadas mostraram-se mais indicadas para papéis em que o índice de tração se faz necessário.

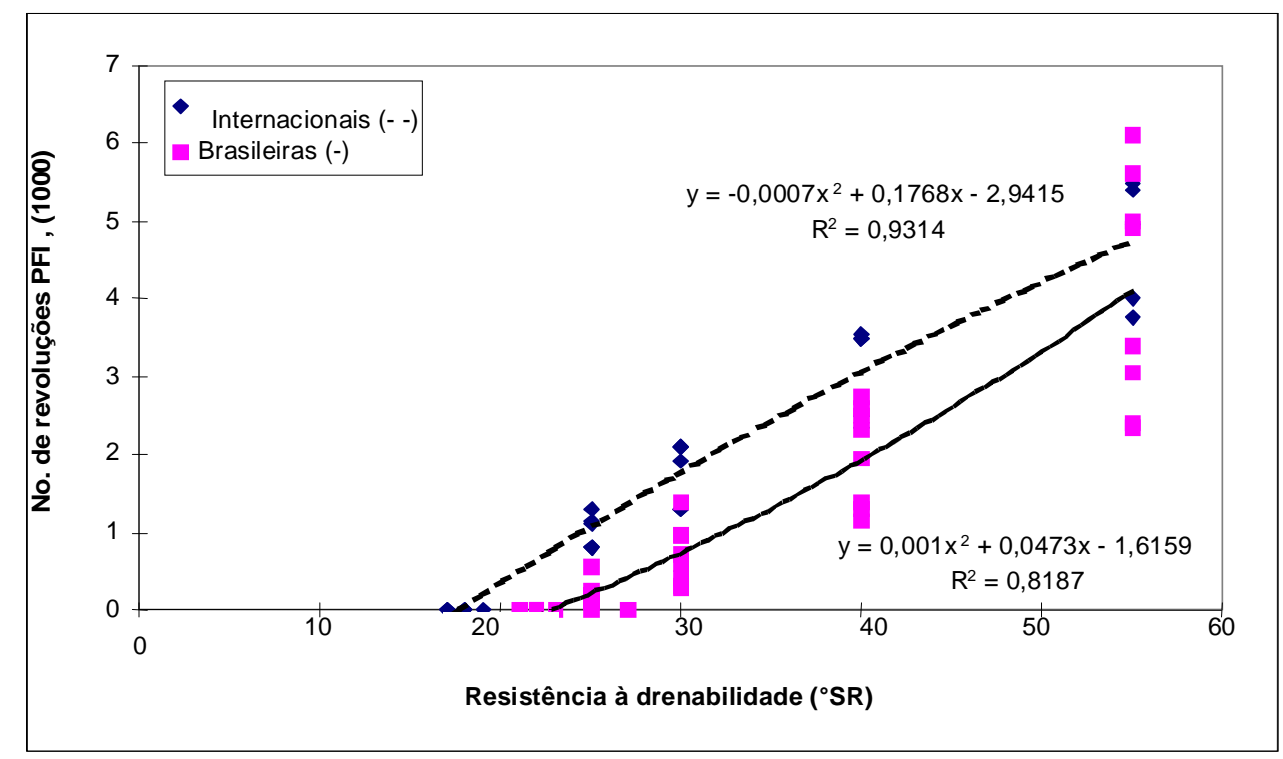

FIGURA 1: Resistência à drenabilidade vs. no. de revoluções da polpa (x 1000).

Na Figura 2, configura-se a tendência das polpas internacionais de apresentarem um maior índice de tração que, apesar da diferença visual observada na curva, só é significativa nos níveis da polpa sem-refino, a $25^{\circ} \mathrm{SR}$ e a $40^{\circ} \mathrm{SR}$. Isso pode ser explicado pelo comprimento médio maior das

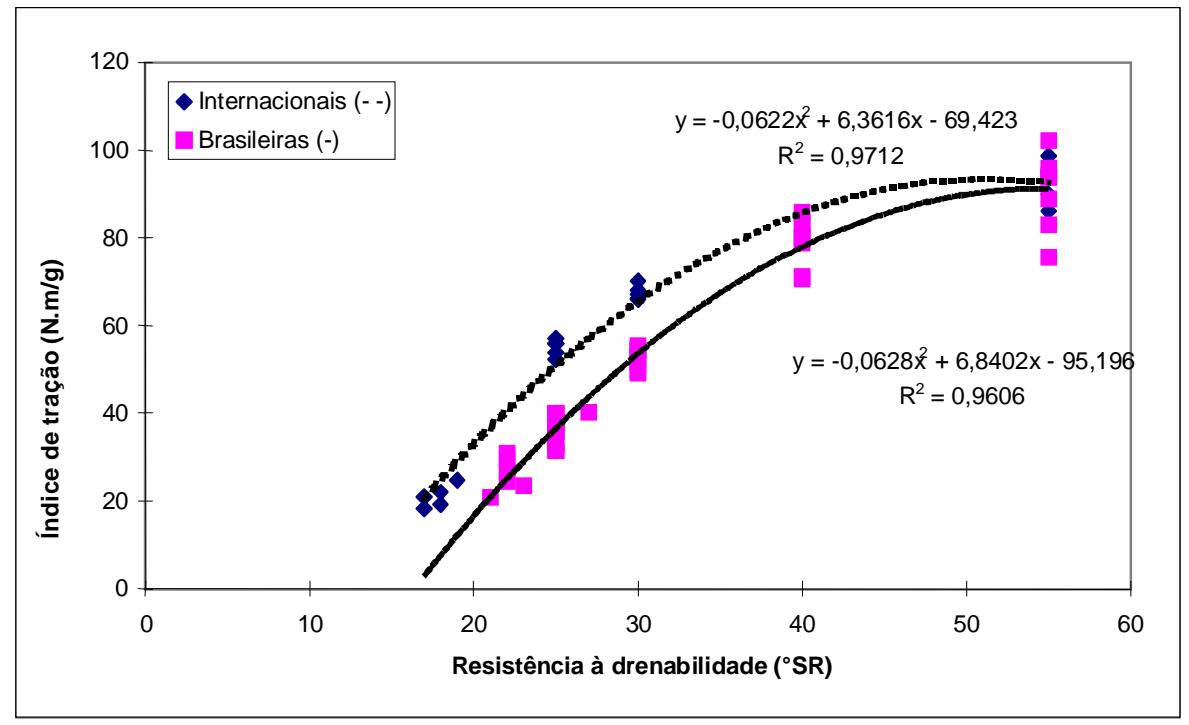

FIGURA 2: Resistência à drenabilidade vs. índice de tração. 
fibras das polpas internacionais $(0,75 \mathrm{~mm})$ em relação às polpas brasileiras $(0,70 \mathrm{~mm})$, pelo maior teor de hemiceluloses (evidenciado pelo $\mathrm{S}_{5}$ ) e pelo maior "coarseness" que indica possivelmente fibras de paredes mais espessas e mais resistentes.

A Figura 3, relacionando tração e alongamento, mostra um comportamento muito semelhante ao da Figura 2, mas de forma que os pontos apareçam melhor distribuídos.

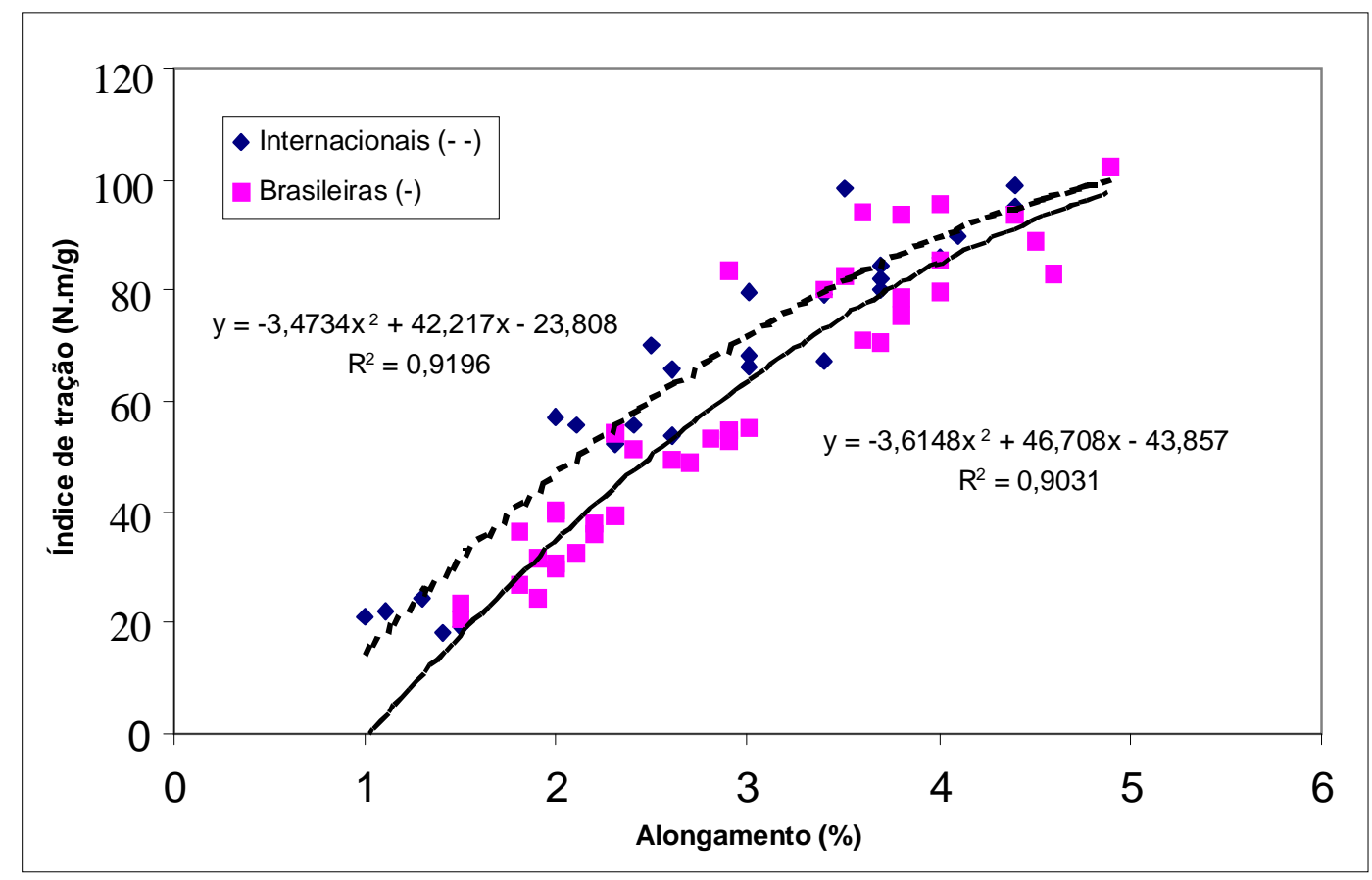

FIGURA 3: Alongamento vs. índice de tração.

Mesmo havendo diferenças significativas entre as médias dos índices de arrebentamento para as polpas brasileiras e internacionais somente no nível inicial e a $25^{\circ} \mathrm{SR}$, o coeficiente de variação para as polpas brasileiras mostrou-se bastante superior em relação às polpas internacionais. Isso ocorre também para as outras propriedades analisadas no refino para a maioria dos casos, porém com valores de coeficientes de variação mais baixos. A razão era a maior heterogeneidade entre a qualidade das polpas brasileiras em razão de processos e matérias-primas.

$\mathrm{Na}$ Figura 4, pode-se visualizar as diferenças entre as polpas brasileiras e internacionais no caso do nível inicial de refino e a $25^{\circ} \mathrm{SR}$, sendo mais fácil visualizar que não há diferenças significativas entre elas para os outros níveis. É interessante notar que, ao nível inicial, a média dos índices de arrebentamento das polpas brasileiras superam fortemente a média das polpas internacionais.

Conforme CASALS (1985), um alto índice de arrebentamento é exigido, quando o impresso a ser realizado se destina a elaboração de bolsas de papel, de livros escolares, envelopes e papéis de embalagem. Como ao nível de $30^{\circ} \mathrm{SR}$, as polpas brasileiras e internacionais não apresentaram 
diferenças significativas, levando-se em conta apenas o seu perfil de arrebentamento, qualquer uma delas poderia ser utilizada para esse tipo de aplicação.

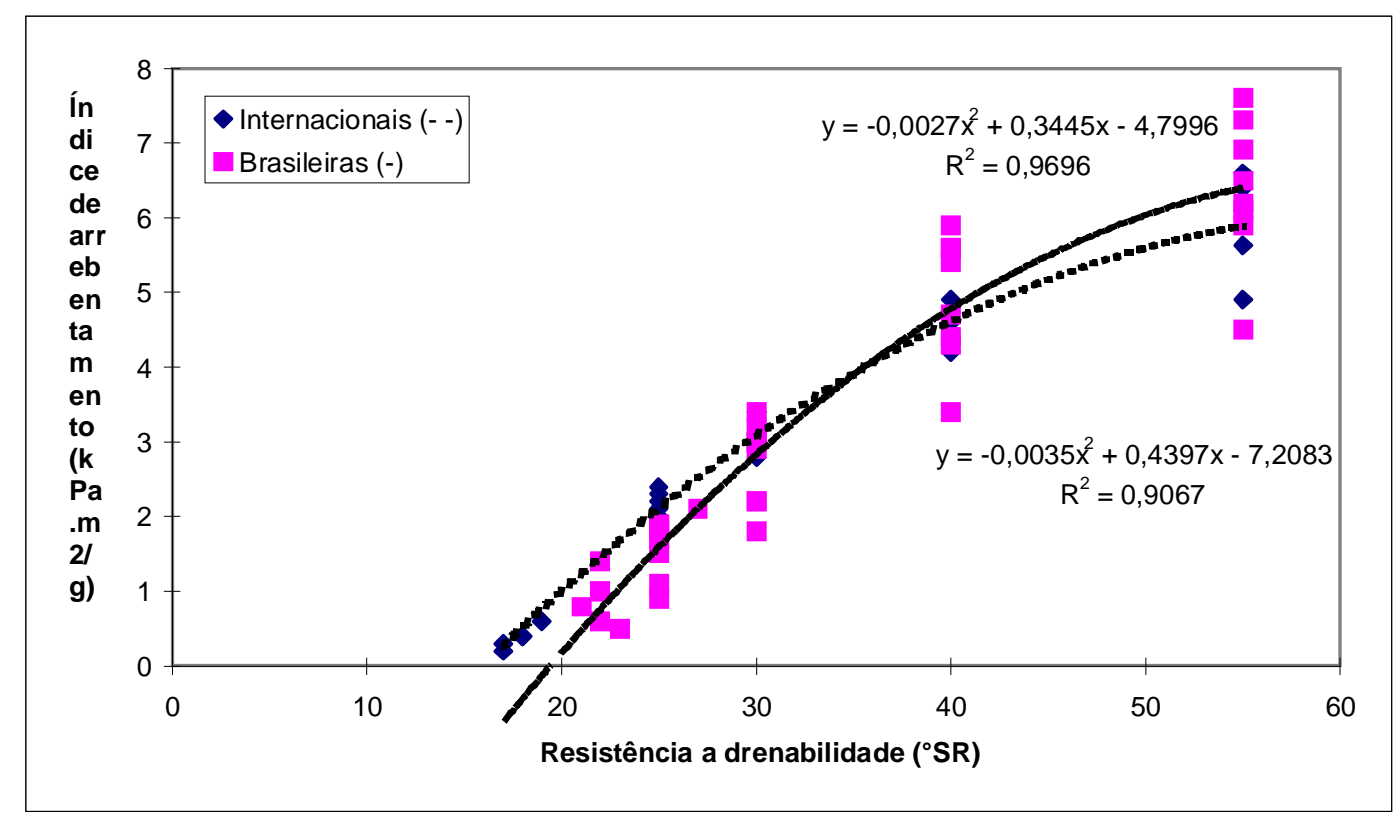

FIGURA 4: Resistência à drenabilidade vs. índice de arrebentamento

O índice de rasgo apresentou comportamento muito semelhante ao índice de tração. A Tabela 1 mostra a diferença significativa entre as médias iniciais dos dois tipos de polpas, com as polpas brasileiras, apresentando valores médios mais altos de índice de rasgo. Entretanto, a $25^{\circ} \mathrm{SR}$ e $30^{\circ} \mathrm{SR}$, as diferenças entre as médias permanecem significativas, havendo, porém, uma superação em termos médios por parte das polpas internacionais. A $40^{\circ} \mathrm{SR}$ e $55^{\circ} \mathrm{SR}$, as diferenças deixam de ser significativas. A Figura 5 permite visualizar melhor esse comportamento

O volume específico médio das polpas brasileiras e internacionais diferiram inicialmente de maneira significativa; não apresentaram diferenças aos níveis de 25 e $30^{\circ} \mathrm{SR}$ e voltaram a diferir significativamente aos níveis de $40^{\circ} \mathrm{SR}$ e $55^{\circ} \mathrm{SR}$. As diferenças dos valores médios de volume específico, entre as polpas ao nível em que ainda não havia refinação, podem ser explicadas pela resistência à drenabilidade, significativamente, maior para as polpas brasileiras em relação às internacionais, nesse nível. 


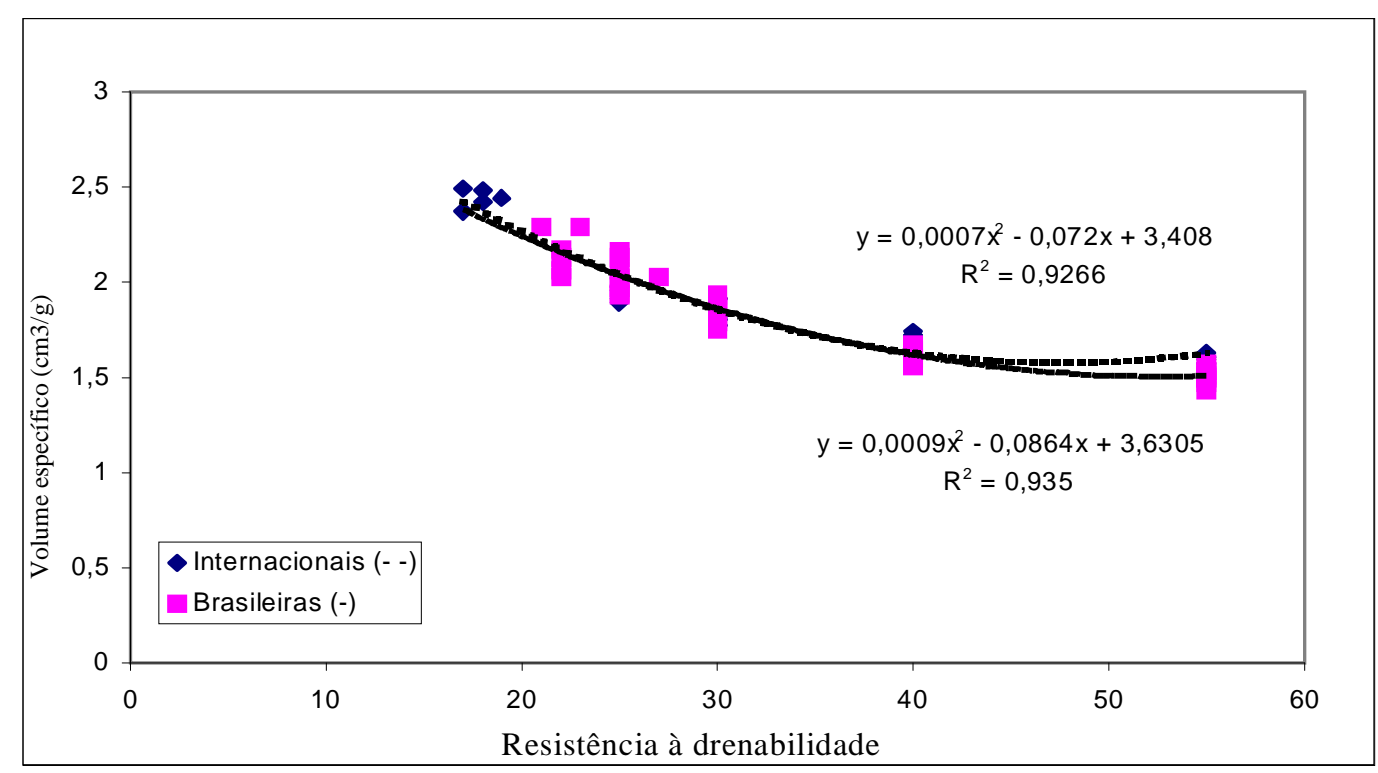

FIGURA 5: Resistência à drenabilidade vs. índice de rasgo.

A Figura 6 mostra que, ao mesmo nível de refino, não se verifica um perfil de curva diferenciado na propriedade de volume específico, mas é importante notar que, acima de $40^{\circ} \mathrm{SR}$, o volume específico tende a estabilizar em torno de $1,5 \mathrm{~cm}^{3} / \mathrm{g}$ aproximadamente. Para os níveis de refino praticados na indústria, tanto as polpas brasileiras como as internacionais podem ser utilizadas para as aplicações em que altos valores de volume específico aparente se fazem necessários.

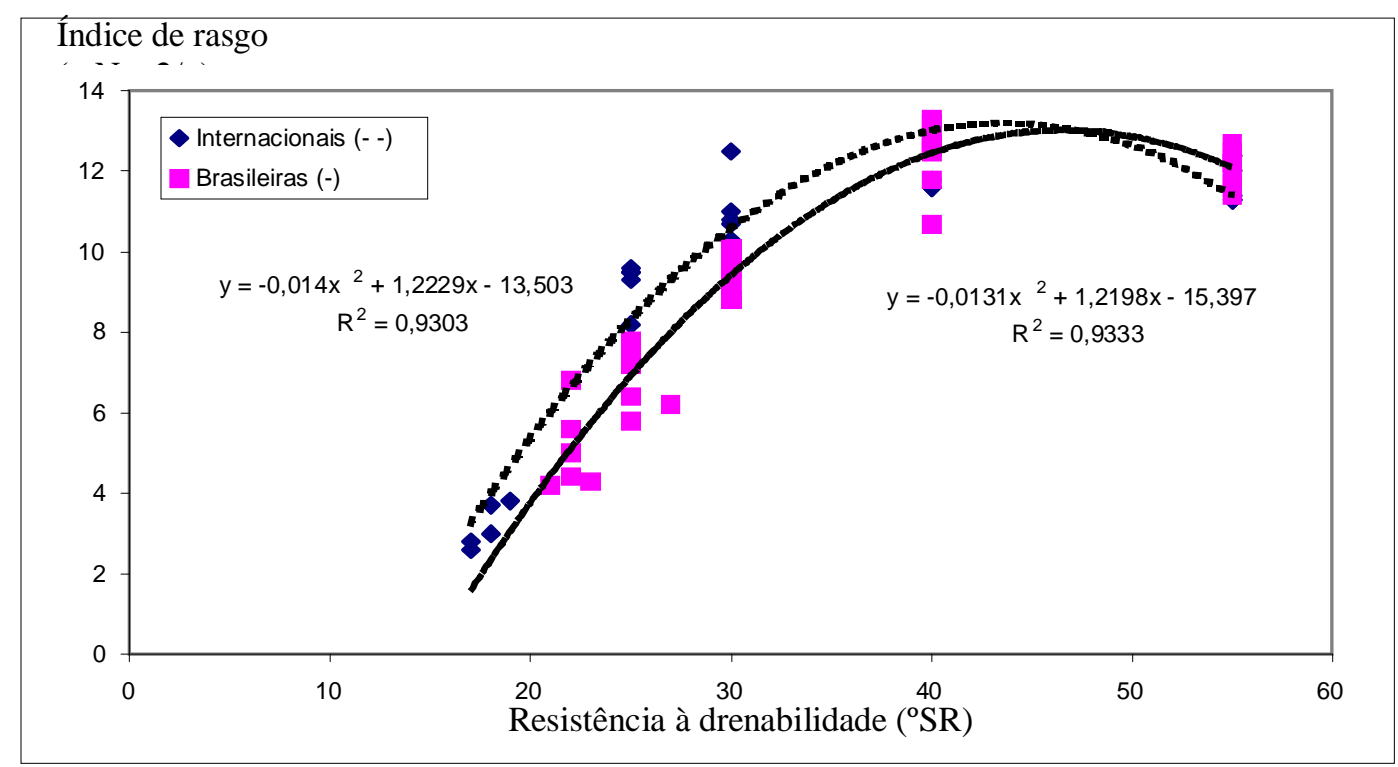

FIGURA 6: Resistência à drenabilidade vs. volume específico. 
A resistência ao ar possui comportamento semelhante ao do volume específico no que diz respeito à significância dos valores médios da polpas brasileiras e internacionais nos vários níveis de refino. Entretanto, as polpas brasileiras superam as polpas internacionais em valores médios, quando há diferença significativa entre elas. Isso significa que dão origem a papéis mais fechados e menos porosos.

A Figura 7 mostra claramente que, aos níveis de 40 e $55^{\circ} \mathrm{SR}$, as polpas brasileiras apresentam maiores valores de resistência ao ar. Um dado importante, que pode ter influenciado esse resultado, é o número inicial de fibras por grama, tanto com corte como sem-corte por causa da maior concentração fibrosa. Somadas a isso, a evolução do refino e a geração de fragmentos de fibras e colapsamento de fibras de paredes mais finas propiciaram a formação de folhas feitas com base nas pastas celulósicas brasileiras, mais fechadas do que as que usaram pastas celulósicas internacionais.

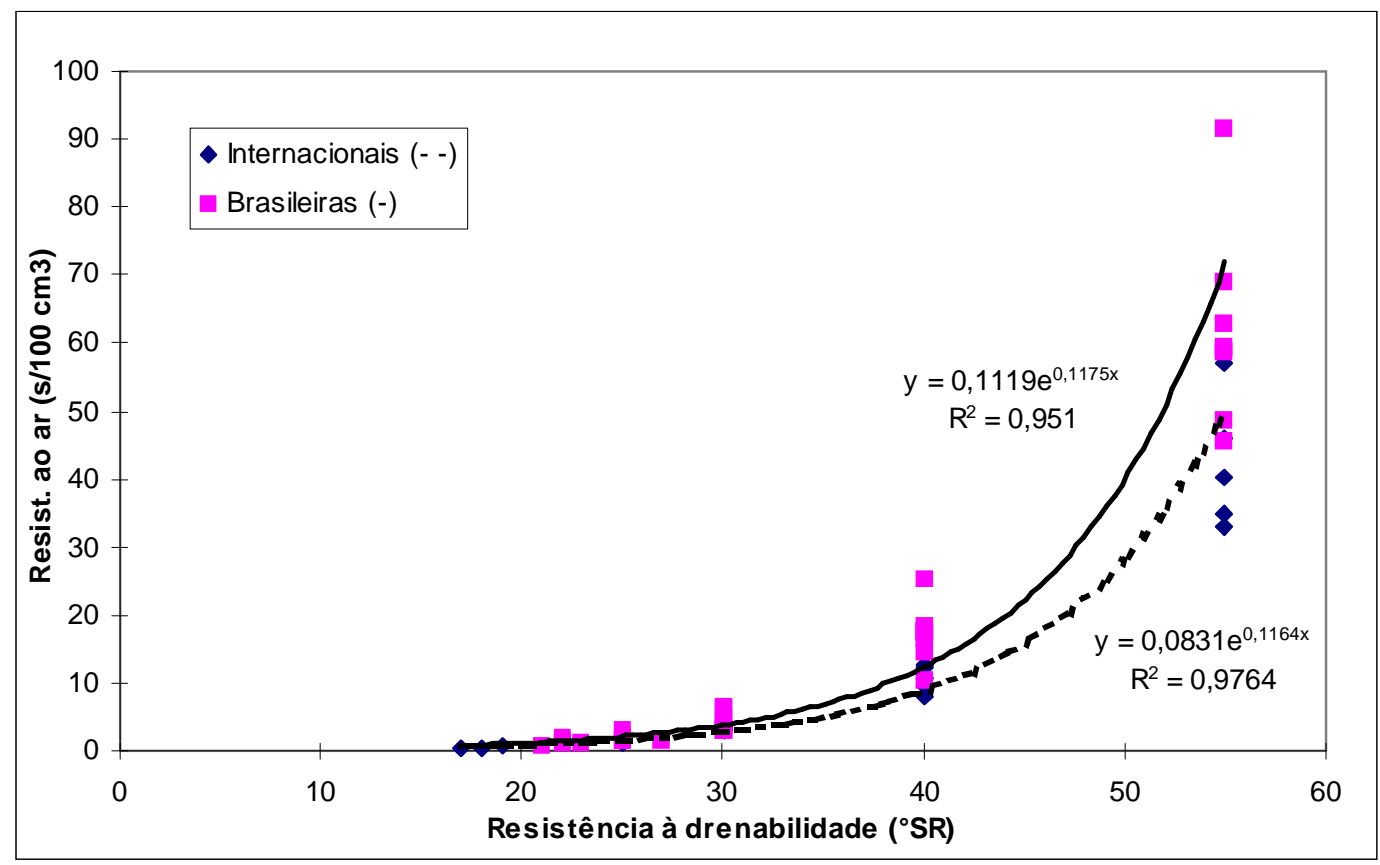

FIGURA 7: Resistência à drenabilidade vs. resistência ao ar.

Segundo ROSSI FILHO (1997), a resistência ao ar afeta a absorção do veículo da tinta. Na impressão em máquinas rotativas, é necessário que a resistência ao ar seja baixa para propiciar rápida penetração do solvente e rápido assentamento da tinta para evitar decalque e riscos no impresso. Outras aplicações requerem papéis menos porosos para evitar penetração excessiva e atravessamento da tinta. Nos níveis mais usuais de refino, para papéis de impressão e escrita, as polpas brasileiras e internacionais foram equivalentes para essa propriedade. 
As médias relativas à opacidade, para as polpas brasileiras e internacionais, apresentam diferenças significativas em nível inicial e a todos os níveis de refino. As polpas brasileiras superam as polpas internacionais em todos esses níveis, conforme pode ser visualizado na Figura 8. Maiores valores de opacidade, apresentados pelas polpas brasileiras podem estar relacionadas com as características anatômicas: maior número de fibras por grama, menor "coarseness" e menor comprimento de fibras.

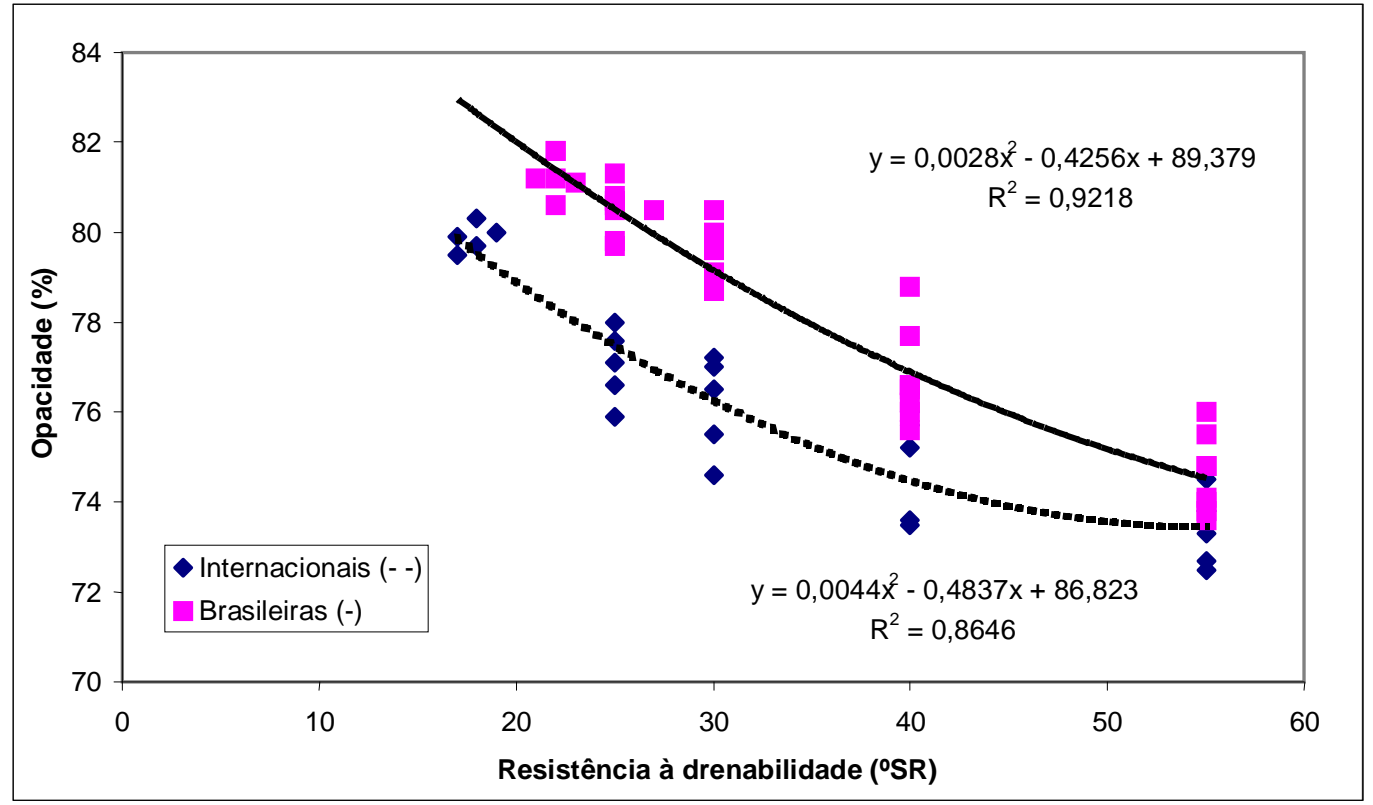

FIGURA 8: Resistência à drenabilidade vs. opacidade.

Segundo ROSSI FILHO (1997), uma alta opacidade é necessária na impressão “offset”, a fim de evitar o inconveniente de aparecer no verso de uma folha de papel a imagem impressa na frente da mesma folha, fato que é agravado, quando se trata de impressões frente e verso.

As médias de ascensão capilar Klemm, das polpas brasileiras e internacionais, apresentaram diferenças significativas apenas no nível inicial, quando as polpas ainda não haviam sido refinadas. É interessante salientar que à medida que as polpas eram refinadas, os valores de ascensão capilar diminuíram, sem que as médias dos valores de ascensão capilar apresentassem diferenças significativas entre as polpas. A Figura 9 mostra de forma clara, esse comportamento. É interessante salientar que, ao nível das polpas ainda não-refinadas, os diferentes valores de ascensão capilar Klemm, entre as polpas brasileiras e internacionais, devem ter sido afetados sensivelmente pelos graus de refino diferenciados para os dois tipos de polpas. 


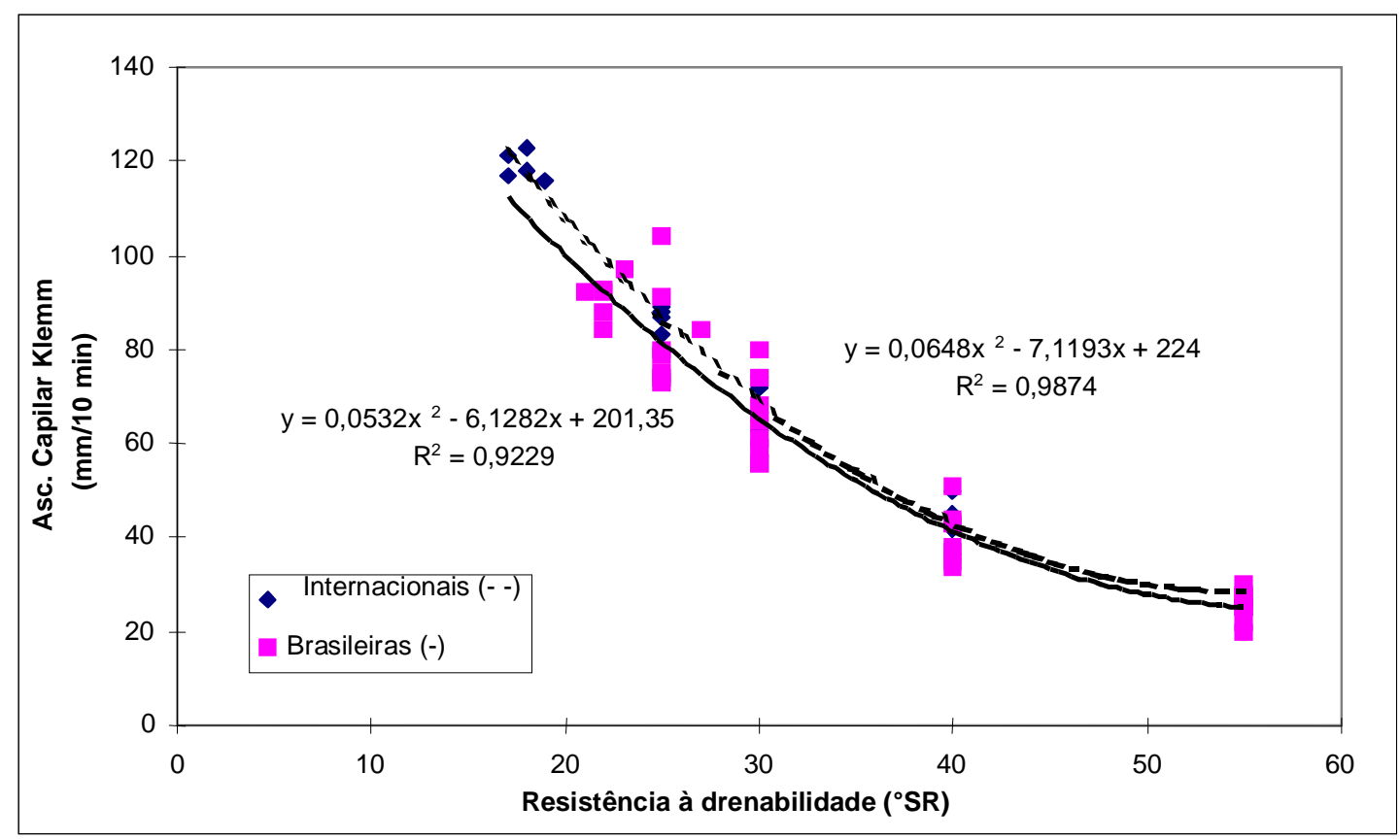

FIGURA 9: Resistência à drenabilidade vs. ascensão capilar Klemm.

\section{Correlações lineares entre as propriedades do refino}

Cada propriedade, que foi considerada ao nível zero de refino e depois a $25^{\circ} \mathrm{SR}, 30^{\circ} \mathrm{SR}$, $40^{\circ} \mathrm{SR} \mathrm{E} 55^{\circ} \mathrm{SR}$, foi relacionada com todas as demais propriedades que sofreram o mesmo tratamento por meio de análise de correlação linear simples, considerando $5 \%$ como nível de significância. O objetivo deste estudo de correlação foi encontrar o melhor nível de refino a ser adotado, buscando eliminar outros níveis menos importantes, e com isso, simplificar o trabalho de caracterização das polpas.

O critério usado foi o de verificar para cada tipo de polpa quais os dois níveis de refino que apresentaram maior número de correlações e, com base nisso, chegar a um nível que fosse comum para as duas polpas. O programa utilizado para a análise de correlação linear simples foi o existente na planilha eletrônica EXCEL, da Microsoft. A Tabela 2 mostra esses resultados, evidenciando que as polpas brasileiras possuem maiores números de correlações para $25^{\circ} \mathrm{SR}$ e $30^{\circ} \mathrm{SR}$, enquanto que para as polpas internacionais essa concentração ocorre valendo-se do nível da polpa não-refinada e $30^{\circ} \mathrm{SR}$.

TABELA 2: Resumo dos números de ocorrência de correlações significativas.

\begin{tabular}{l|c|c|c|c|c}
\hline POLPAS & Sem refino & $25^{\circ} \mathrm{SR}$ & $30^{\circ} \mathrm{SR}$ & $40^{\circ} \mathrm{SR}$ & $55^{\circ} \mathrm{SR}$ \\
\hline Brasileiras & 70 & 116 & 99 & 61 & 58 \\
Internacionais & 97 & 74 & 102 & 82 & 77 \\
\hline Total & 167 & 190 & 201 & 143 & 135 \\
\hline
\end{tabular}


Uma vez definido um nível referencial de refino, foram feitas correlações entre as propriedades intrínsecas das pastas celulósicas e as demais propriedades, como mostra a Tabela 3.

TABELA 3: Matriz de correlação das propriedades intrínsecas com as propriedades analisadas ao nível de refino de $30^{\circ} \mathrm{SR}$.

\begin{tabular}{|c|c|c|c|c|c|c|c|c|c|}
\hline Descrições & $\begin{array}{l}\vec{I} \\
\dot{a} \\
\dot{0} \\
\overrightarrow{0} \\
\tilde{c}\end{array}$ & 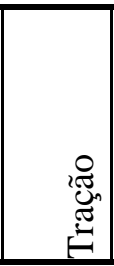 & 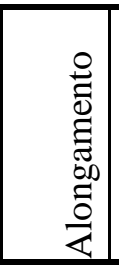 & 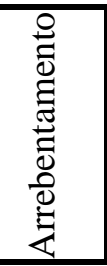 & 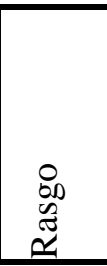 & $\begin{array}{l}\dot{0} \\
0 \\
0 \\
\text { II } \\
\dot{0} \\
\dot{3}\end{array}$ & 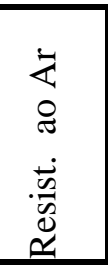 & 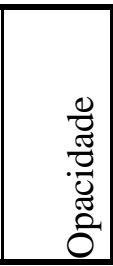 & 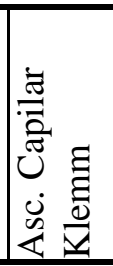 \\
\hline \multicolumn{10}{|c|}{ POLPAS BRASILEIRAS } \\
\hline VISCOSIDADE INTRÍNSECA (cm3/g) & $-0,694$ & $-0,070$ & 0,012 & $-0,147$ & $-0,211$ & 0,318 & 0,220 & 0,329 & 0,230 \\
\hline S5 $(\%)$ & $-0,675$ & 0,235 & $-0,033$ & 0,101 & $-0,043$ & 0,048 & 0,393 & 0,166 & 0,184 \\
\hline COARSENESS $(\mathrm{mg} / 100 \mathrm{~m}) \mathrm{c} /$ corte & 0,571 & 0,123 & 0,418 & $-0,097$ & 0,359 & $-0,291$ & $-0,056$ & $-0,261$ & $-0,310$ \\
\hline COARSENESS $(\mathrm{mg} / 100 \mathrm{~m}) \mathrm{s} /$ corte & 0,595 & 0,076 & 0,400 & $-0,089$ & 0,278 & $-0,246$ & $-0,154$ & $-0,314$ & $-0,322$ \\
\hline NÚMERO DE FIBRAS (milhões)/g c/ corte & $-0,583$ & $-0,176$ & $-0,287$ & 0,013 & $-0,403$ & 0,180 & 0,140 & 0,378 & 0,176 \\
\hline NÚMERO DE FIBRAS (milhões)/g s/ corte & $-0,470$ & $-0,085$ & $-0,265$ & 0,193 & $-0,242$ & 0,035 & 0,198 & 0,307 & 0,122 \\
\hline COMPRIMENTO MÉDIO DA FIBRA (mm) & $-0,101$ & 0,550 & 0,024 & 0,321 & 0,410 & 0,046 & 0,386 & $-0,539$ & $-0,025$ \\
\hline DPCJ $(\%)$ & 0,639 & 0,461 & 0,350 & 0,294 & 0,328 & $-0,740$ & 0,214 & $-0,407$ & $-0,444$ \\
\hline \multicolumn{10}{|c|}{ POLPAS INTERNACIONAIS } \\
\hline VISCOSIDADE INTRÍNSECA (cm3/g) & 0,534 & 0,622 & $-0,544$ & 0,807 & 0,111 & $-0,656$ & $-0,564$ & $-0,642$ & $-0,585$ \\
\hline $\mathrm{S} 5(\%)$ & $-0,426$ & $-0,177$ & $-0,222$ & $-0,464$ & 0,116 & 0,840 & $-0,317$ & $-0,005$ & 0,630 \\
\hline COARSENESS $(\mathrm{mg} / 100 \mathrm{~m}) \mathrm{c} /$ corte & 0,547 & $-0,025$ & 0,623 & 0,598 & 0,482 & $-0,627$ & $-0,104$ & $-0,141$ & $-0,556$ \\
\hline COARSENESS $(\mathrm{mg} / 100 \mathrm{~m}) \mathrm{s} /$ corte & 0,587 & 0,085 & 0,457 & 0,691 & 0,404 & $-0,743$ & $-0,145$ & $-0,205$ & $-0,633$ \\
\hline NÚMERO DE FIBRAS (milhões)/g c/ corte & $-0,534$ & $-0,198$ & $-0,195$ & $-0,679$ & $-0,132$ & 0,867 & 0,030 & 0,166 & 0,673 \\
\hline NÚMERO DE FIBRAS (milhões)/g s/ corte & $-0,804$ & $-0,548$ & $-0,086$ & $-0,894$ & $-0,229$ & 0,957 & 0,158 & 0,543 & 0,894 \\
\hline COMPRIMENTO MÉDIO DA FIBRA (mm) & 0,208 & 0,682 & $-0,760$ & 0,257 & $-0,155$ & $-0,052$ & $-0,327$ & $-0,607$ & $-0,186$ \\
\hline DPCJ $(\%)$ & $-0,354$ & 0,090 & $-0,268$ & $-0,598$ & $-0,313$ & 0,652 & 0,261 & 0,026 & 0,429 \\
\hline
\end{tabular}

POLPAS BRASILEIRAS E INTERNACIONAIS

\begin{tabular}{llllllllll}
\hline VISCOSIDADE INTRÍNSICA $\left(\mathrm{cm}^{3} / \mathrm{g}\right)$ & 0,346 & 0,477 & $-0,105$ & 0,173 & 0,285 & $-0,316$ & $-0,081$ & $-0,384$ & 0,044 \\
S5 (\%) & 0,266 & 0,731 & 0,079 & 0,219 & 0,462 & 0,015 & $-0,237$ & $-0,514$ & 0,443 \\
COARSENESS (mg/100m) c/ corte & 0,812 & 0,662 & 0,598 & 0,394 & 0,742 & $-0,407$ & $-0,123$ & $-0,648$ & $-0,251$ \\
COARSENESS (mg/100m) s/ corte & 0,826 & 0,606 & 0,544 & 0,385 & 0,658 & $-0,397$ & $-0,208$ & $-0,654$ & $-0,308$ \\
NÚMERO DE FIBRAS (milhões)/g c/ corte & $-0,896$ & $-0,799$ & $-0,385$ & $-0,476$ & $-0,742$ & 0,266 & 0,351 & 0,788 & 0,047 \\
NÚMERO DE FIBRAS & $-0,872$ & $-0,717$ & $-0,352$ & $-0,296$ & $-0,646$ & 0,163 & 0,430 & 0,757 & 0,046 \\
COMPRIMENTO MÉDIO DA FIBRA (mm) & 0,668 & 0,720 & $-0,113$ & 0,268 & 0,483 & 0,284 & $-0,721$ & $-0,774$ & 0,461 \\
DPCJ (\%) & $-0,441$ & $-0,208$ & $-0,018$ & $-0,112$ & $-0,384$ & $-0,061$ & 0,503 & 0,279 & $-0,158$ \\
\hline
\end{tabular}

Ficou evidenciado, dentro das faixas apresentadas neste estudo, que, quando as polpas são analisadas separadamente, há poucas correlações significativas entre as propriedades descritas acima. 
Entretanto, quando as polpas brasileiras e internacionais são analisadas conjuntamente, evidenciamse as importâncias do "coarseness", número de fibras por grama e comprimento médio da fibra.

\section{CONCLUSÕES}

Para a faixa de viscosidade intrínseca de 672 a $898 \mathrm{~cm}^{3} / \mathrm{g}$, não se evidenciou correlação entre essa propriedade e as associadas com o grau de interligação entre as fibras, como por exemplo: índice de tração, índice de rasgo e índice de arrebentamento, para cada grupo de polpas de eucalipto avaliadas (brasileiras e internacionais). Quando as polpas são analisadas em conjunto, não se evidenciou correlações que possam prever os comportamentos dessas propriedades em função da viscosidade intrínseca.

$\mathrm{Na}$ faixa de $\mathrm{S}_{5}$ (indicação indireta do teor de hemiceluloses das pastas celulósicas) entre 8,0 e $13,7 \%$, não se evidenciou correlação entre essa propriedade e aquelas que estejam associadas com o grau de interligação de fibras, para cada grupo avaliado (polpas brasileiras e polpas internacionais). Entretanto, quando as polpas são analisadas em conjunto, observa-se que existe uma correlação positiva aos níveis de refino de 25 e $30^{\circ} \mathrm{SR}$ para o índice de tração, e aos níveis de 25 e $55^{\circ} \mathrm{SR}$ para o índice de rasgo.

As celuloses de eucaliptos brasileiras apresentam uma maior drenabilidade inicial, requerendo um menor número de revoluções para atingir o mesmo grau de refino em relação às polpas internacionais. Os valores médios iniciais, do índice de tração, do índice de arrebentamento, do índice de rasgo e alongamento apresentados pelas celuloses brasileiras superaram significativamente os valores obtidos para as celuloses internacionais, mudando, porém, esse comportamento já com base $n$ o nível de $25^{\circ} \mathrm{SR}$.

No nível referencial de $30^{\circ} \mathrm{SR}$, as celuloses de eucalipto internacionais apresentaram uma superioridade nas propriedades de rasgo e tração, passando a ser indicadas para os segmentos de impressão em que essas propriedades se fazem necessárias.

Todavia, os maiores valores em opacidade no nível referencial valorizam o uso das celuloses brasileiras. Portanto, cabe ao fabricante determinar qual o conjunto de propriedades mais adequado ao seu processo e produto.

Como conclusão final, tomando-se o maior valor do número de correlações, identificou-se para as celuloses de eucalipto que o nível de $30^{\circ} \mathrm{SR}$ permite projetar o desempenho ao longo de todo o refino para as propriedades físico-mecânicas e opacidade. Tal escolha permite uma diminuição do corrente número de refinações realizadas em laboratório. Dentro dessa diretriz, a concentração nos testes de índice de tração, índice de rasgo e opacidade também reduzirá o número de análises empregadas para avaliar esse tipo de matéria-prima. 


\section{REFERÊNCIAS BIBLIOGRAFIAS}

ANNIKKI, H.; LEVLIN, J.E.; HANNU, P. Principles and methods in pulp characterization: basic fiber properties. In: EUCEPA CONFERENCE, 24., 1990, Stockholm. Proceedings ... Stockholm: The Swedish Association of Pulp and Paper Engineers, 1990. p. 174-187.

CARPIM, M.A.; BARRICHELLO, L.E.G.; SILVA JR., C. et al. A influência do número de fibras por grama nas propriedades óticas do papel. In: CONGRESSO ANUAL DA ASSOCIAÇÃO TÉCNICA BRASILEIRA DE CELULOSE E PAPEL, 20., 1987, São Paulo. Anais ... São Paulo: Associação Técnica Brasileira de Celulose e Papel, 1987. p. 183-205.

CASALS, R. Características del papel. Barcelona: Howson - Algraphy, 1985. 174 p.

D'ALMEIDA, M.L.O. Viscosidade de uma pasta celulósica e a resistência do papel formado. $\mathbf{O}$ Papel, p. 39-42, ago. 1986.

DASGUPTA, S. Mechanism of paper tensile-strength development due to pulps beating. Tappi Journal, v. 77, n. 6, p.158-166, Jun. 1994.

EQUIPE DEPDEC. Medição do mínimo comprimento de fibra de Eucalyptus saligna e Eucalyptus grandis. Guaíba: Riocell, 1989. 12 p. (Nota Técnica).

HORTAL, J.G. Constituyentes fibrosos de pastas y papeles. Terrassa: Escuela Técnica Superior de Ingenieros Industriales de Terrassa, 1988. 186 p. Cap. 2, p. 11-36: Composición química y estructura de la fibra.

INTERNATIONAL ORGANIZATION FOR STANDARDIZATION. Paper and board: measurement of diffuse blue reflectance factor (ISO brightness). Genève, 1977. 4p. (ISO 2470: 1977).

Cellulose in dilute solutions: determination of limiting viscosity number. Part 1 : Method in cupriethylene- diamine (CED) solution. Genève, 1981. 11p. (ISO 5351-1 : 1981).

. Paper and board: determination of grammage. Genève, 1979. 4p. (ISO $536: 1979$ ).

. Paper and board: determination of opacity- Diffuse reflectance method. Genève, 1977. 5p. (ISO 2471 : 1977).

. Paper and board: determination of tensile properties. Part 1 : constant rate of loading method. Genève, 1992. 5p. (ISO 1924-1 : 1992).

. Paper and board: determination of tensile properties. Part 2: constant rate of elongation method. Genève, 1992. 6p. (ISO 1924-2 : 1994).

_. Paper: determination of tearing resistance (Elmendorf method). Genève, 1980. 8p. (ISO 1974 : 1990).

_. Pulps: determination of alkali solubility. Genève, 1982. 4p. (ISO 692 : 1982).

Pulps: determination of drainability. Part 1: Schopper-Riegler method. Genève, 1979. 5p. (ISO 5267-1 : 1979). 
_. Pulps: Laboratory beating. Part 2: PFI mill method. Genève, 1979. 5p. (ISO 5264-2 : 1979).

Cellulose in dilute solutions: determination of limiting viscosity number. Part 1 : Method in cupriethylene- diamine (CED) solution. Genève, 1981. 11p. (ISO 5351-1 : 1981).

JIMÉNEZ, J.R. Los controles en la fabricación del papel. Madrid: Blume, 1970. 361 p. Cap.12, p.199-249: Relación entre las características de las pastas y los papeles.

KEREKES, R. J.; SCHELL, C.J. Effects of fiber length and coarseness on pulp flocculation. Tappi Journal, v.78, n.2, p.133-139, Feb. 1995.

LEVLIN, J.E. The characterization of papermaking pulps. Tappi, v.58, n.1, p. 71-74, Jan. 1975.

NEVELL, T.P.; ZERONIAN, S.H. Celulose chemistry and its applications. New York: John Wiley \& Sons, 1985.

RETULAINEN, E., EBELING, K. Fibre bonding and ways of characterizing bond strength. Appita, v. 46, n. 4, p. 282-288, jul.1993.

ROSSI FILHO, S. Impressões offset: soluções práticas. Porto Alegre: Colégio de Formação Profissional SENAI de Artes Gráficas Henrique d'Ávila Bertaso, 1997. 127 p.

SAUCEDO, J. J.; GONZÁLEZ, S.F. Identificación y efecto de las hemiceluloses sobre las propriedades físicas de la celulosa y papel. In: CONGRESO LATINOAMERICANO DE CELUlOSA Y PAPEL, 2., 1981, Torremolinos. Anais ... Torremolinos: Asociación de Investigación Técnica de la Indústria Papelera Española, 1981. p. 143-151.

SCOTT, W. E.; TROSSET, S. Properties of paper: an introduction. Atlanta: Tappi, 1989. 170 p.

SETH, R. S. The importance of fibre coarseness for pulp properties. In: ANNUAL MEETING, 77. 1991, Montreal. Proceedings ... Montreal: Canadian Pulp and Paper Association, 1991. p. 251252.

TECHNICAL ASSOCIATION OF PULP AND PAPER INDUSTRY. Air resistance of paper. Atlanta: Tappi, 1994. 3 p. (T460 om-88).

. Bursting strength of paper. Atlanta: Tappi, 1994. 4 p. (T403 om-91).

Forming handsheets for physical tests of pulp. Atlanta: Tappi, 1994. 3 p (T205 om-88).

Sampling and accepting a single lot of paper, paperboard, fiberboard ou related product. Atlanta: Tappi, 1989. 5 p (T400 om-85).

Thickness (caliper) of paper, paperboard and combined board. Atlanta, 1989. 3 p. (T411 om-89).

Sampling and accepting a single lot of paper, paperboard, fiberboard ou related product. Atlanta: Tappi, 1989. 5 p (T400 om-85).

TASMAN, J. E. Pulp and paper manufacture: mill control and control systems. Atlanta: Tappi, 1992. 430 p. Cap. 2, p. 48-84: Evaluation of raw materials and product quality.

YOUNG, J. H. Pulp and paper: chemistry and chemical technology. 3 ed., New York: John Wiley \& Sons, 1980. 1446 p. Cap. 6: Fiber preparation and approach flow. 